\title{
Synthesis and Photocyclization of [2.0.2.0]-, [2.2.2.0]- and
}

\section{[2.2.2.2]Cyclophanediene}

\author{
BENGT THULIN and OLOF WENNERSTRÖM
}

Department of Organic Chemistry, Chalmers University of Technology and University of Göteborg, S-412 96 Göteborg, Sweden

Three cyclophanes, [2.0.2.0]-, [2.2.2.0]- and [2.2.2.2]cyclophanediene, 1,5 and 6 , respectively, have been prepared by double Wittig reactions. On irradiation under oxidative conditions, cyclophanes 1 and 6 give bi-4,5-phenanthrylene, 2 , and $[2.2](3,6)$-phenanthreneophane, 7 , respectively. On further oxidation of 2 , dibenzo[def,$p q r]$ cyclobutano $[j k l]$ tetraphenylene, $\quad 4, \quad$ is formed.

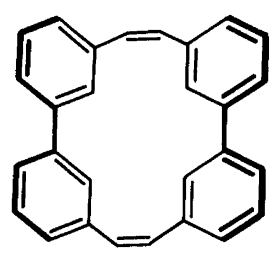

IA<smiles>C1=Cc2cccc(c2)-c2cccc(c2)/C=C/c2cccc(c2)-c2cccc1c2</smiles>

IC<smiles></smiles>

IB

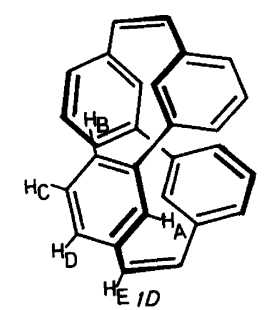
clization of three cyclophenadienes. The conformations of the cyclophanes are discussed briefly in relation to the photocyclizations. Part of this work has been reported in a short communication. $^{2}$

\section{RESULTS AND DISCUSSION}

[2.0.2.0]Metacyclophanediene, 1 , can be prepared in $4 \%$ yield from biphenyl-3,3'-dialdehyde and the bis triphenylphosphonium salt from 3,3'-bis(bromomethyl)biphenyl by a double Wittig reaction at $-40^{\circ} \mathrm{C} .^{2}$ An alternative but longer synthetic route via the dithiacyclophane and ring contraction rearrangements has been described by Leach and Reiss. ${ }^{3}$ The structure of the cyclophane follows from its ${ }^{1} \mathrm{H}$ NMR, UV and MS. The conformation of 1 is of interest when 
it is not possible to discriminate between the four conformers $1 A-1 D$. Although the internal aromatic protons appear at unusually low field $(\delta$ 7.61) this shift can be attributed either to proximity effects in $1 A$ or $1 C$ or to deshielding effects from neighbouring phenyl rings in $1 B$ or $1 D$. However, the UV spectrum of 1 is similar to that of cis-stilbene, with almost double the $\varepsilon$-value (see Experimental) which is to be expected only for conformer $1 D$.

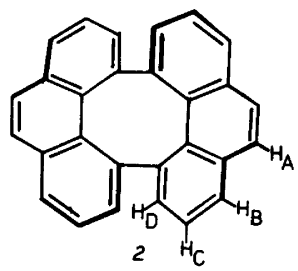

Irradiation of cyclophane 1 under oxidative conditions gave bi-4,5-phenanthrylene, 2, (or dibenzo[def,pqr]tetraphenylene) in $65 \%$ yield. The product must be rather strained and the two twisted phenanthrene (or 3 helicene) units could be almost orthogonal giving the molecule a propeller-shaped structure $\left(D_{2}\right.$-symmetry) similar to that of its precursor. This proposal is supported by the UV spectrum of 2 which closely resembles that of phenanthrene. A recent X-ray investigation of 2 shows that the internal deformations of the two phenanthrene subunits are similar to those found in helicenes and that the angle between the two phenanthrene moieties is $69^{\circ} .{ }^{4}$ The ${ }^{1} \mathrm{H}$ NMR spectrum of 2 is also similar to that of phenanthrene except for the signal from the $\mathrm{H}_{\mathrm{D}}$-protons which is shifted upfield by 0.98 ppm. This shift is probably due to shielding by the opposite phenanthrene unit in the severely twisted structure.

It is conceivable that irradiation of cyclophane 1 under nonoxidative conditions (degassed solution, nitrogen atmosphere) would lead to two successive photocyclizations to give a product with two dihydrophenanthrene units linked together to form a ring. Such an unstable intermediate, ideally with $D_{2}$-symmetry, sould be considered as a bridged [24]annulene, 3. However, we have not been able to detect such an intermediate on irradiation of 1 . Instead, we observed a slow decomposition of the starting material and initially some cis-trans isomerization (NMR evidence only).

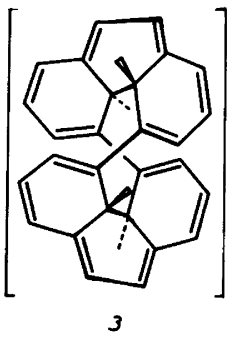

Oxidation of 2 in a melt of sodium chloride and aluminium trichloride ${ }^{5}$ gave 4 , dibenzo[def,pqr]cyclobutano[ $j k l]$ tetraphenylene, the structure of which was determined by ${ }^{1} \mathrm{H}$ NMR and MS (see Experimental). The NMR spectrum of 4 resembles those of the dehydrohelicenes prepared by Wynberg and co-workers. ${ }^{6}$ The MS of 4 is very simple, showing $\mathrm{M}^{+}$and $\mathrm{M}^{2+}$ and almost no fragmentation, which reflects the stability of the compound. Further oxidation of 4 to the fully ring-closed derivative was unsuccessful. In contrast to that of 4 the MS of 1 and 2 showed not only strong molecular ions but the successive loss of six and two mass units, respectively, interpreted as being due to ring closure reactions. The same ring closures could be achieved by irradiation and oxidation. Thus, there seems to be a close parallel between facile ring-closure reactions in the mass spectrometer and chemicallyinduced reactions in these compounds.
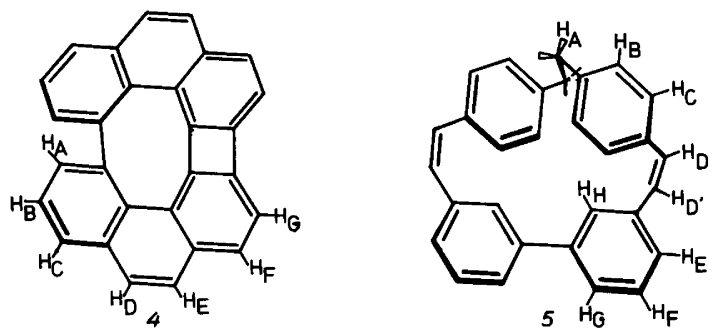

In order to increase the flexibility of the cyclophanediene and its ring-closed derivatives, we prepared a new cyclophane in which one of the biphenyl units in 1 had been replaced by a bibenzyl unit. The bis(triphenylphosphonium) salt from 3,3'-bis(bromomethyl)biphenyl was reacted with bibenzyl-4,4'-dialdehyde under the standard conditions to give [2.2.2.0]metaparacyclophanediene, 5 , in $4 \%$ yield after chromatography. To our surprise, irradiation of 5 in various solvents under oxidative conditions gave 
no ring closed product. Instead, slow decomposition of the starting material and, possibly, cistrans isomerization was observed. It is difficult to rationalize the failure of the photocyclization as being due to unfavourable geometry in the ground state. Although no certain conclusions about the ground state geometry can be drawn from available data, there seems to be little steric hindrance in a conformation with two cis-stilbene units (from CPK models). Thus, since the UV spectrum of 5 is consistent with such a conformation, we are left with the speculation that unfavourable steric effects in the excited state prevent the photocyclization reaction. ${ }^{7}$

An even more flexible cyclophanediene, cis, cis-[2.2.2.2]paracyclophanediene, 6 , can be prepared by a double Wittig reaction from bibenzyl-4,4'-dialdehyde and the bis(triphenylphosphonium) salt from 4,4'-bis(bromomethyl)bibenzyl. The same cyclophane has also been prepared by preparative electrolysis at constant potential of [2.2.2.2] paracyclophanetetraene ${ }^{8}$

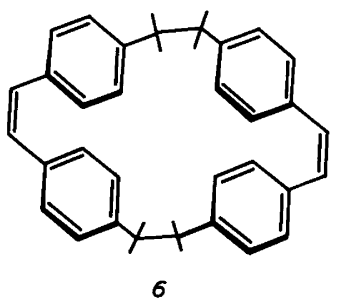

and by light-induced isomerization of the trans,trans isomer of [2.2.2.2] paracyclophanediene. ${ }^{9}$ We have also reported on the conformations and dynamic processes in the cis,cis isomer of [2.2.2.2]paracyclophanediene, 6 , elsewhere ${ }^{10}$ As expected, the cyclophanediene 6 readily undergoes photocyclizations under oxidative conditions to give $[2.2](3,6)$ phenanthrenophane, 7 , which can also be prepared by catalytic hydrogenation of $[2.2](3,6)$ phenanthrenophanediene. ${ }^{11}$ The cyclophane 7 is rather rigid and
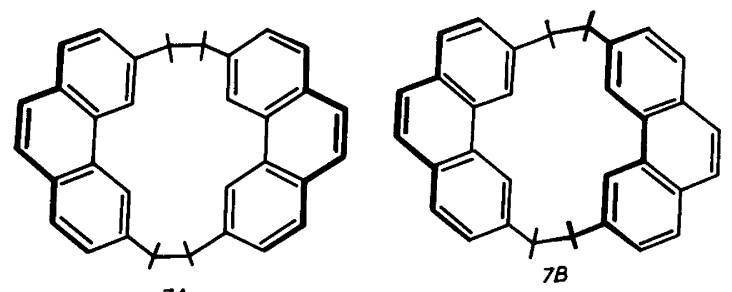

should adopt a syn. $7 A$, or anti, $7 B$, conformation. The downfield shift of the methylene protons in $7(\delta 3.62)$ as compared to those observed in a series of similar cyclophanes with ethylene bridges ${ }^{10}$ is best explained by assuming the syn conformation to be lowest in energy. If so, exchange of the "outer" and "inner" methylene protons in 7 to give a singlet in the NMR spectrum, requires a rapid inversion process via the anti conformation.

\section{EXPERIMENTAL}

${ }^{1} \mathrm{H}$ NMR spectra were recorded on a Bruker WH 270 instrument using $\mathrm{CDCl}_{3}$ as solvent and TMS as internal standard. Mass spectra were run on an AEI MS 902 spectrometer and UV spectra (in cyclohexane unless otherwise stated) on a Beckman DK-2A instrument. Melting points were determined on a Reichert hot stage apparatus. The photochemical experiments were carried out using a Rayonet reactor with light of maximum intensity at $254 \mathrm{~nm}$ and $300 \mathrm{~nm}$.

The bis(triphenylphosphonium) salt from 3,3'bis(bromomethyl)biphenyl. 3,3'-Dimethylbiphenyl $(0.05 \mathrm{~mol})$, recrystallized $N$-bromosuccinimide $(0.11 \mathrm{~mol})$ and dibenzoylperoxide, as initiator, were refluxed for $24 \mathrm{~h}$ in dry, redistilled, tetrachloromethane. The hot solution was filtered to remove succinimide, and 3,3'-bis(bromomethyl)biphenyl precipitated from the cooled filtrate $\left(38 \%\right.$, m.p. $114-115^{\circ} \mathrm{C}$, NMR: $\delta 7.6-7.3(8 \mathrm{H}, \mathrm{m}), 4.54(4 \mathrm{H}, \mathrm{s}))$. The product was then heated in dry DMF with two equivalents of triphenylphosphine for $10 \mathrm{~h}$. On cooling of the reaction mixture, the white crystalline phosphonium salt precipitated. This was collected, washed with dry ether, and dried in vacuo before use.

The bis(triphenylphosphonium) salt from 4,4'bis(bromomethyl)bibenzyl was prepared from $4,4^{\prime}$-bibenzyldicarbaldehyde. Reduction of the dialdehyde with $\mathrm{LiAlH}_{4}$ gave the hydroxymethyl compound which was converted to the corresponding bromomethyl compound by treatment with $\mathrm{HBr}$ in acetic acid. The bis(bromomethyl) compound was then heated with two equivalents of triphenylphosphine in dry DMF for $12 \mathrm{~h}$, and the reaction mixture cooled. The precipitated bisphosphonium salt was collected, washed with ether, and dried in vacuo before use.

3,3'-Biphenyldicarbaldehyde. The crude 3,3'bis(dibromomethyl)biphenyl prepared by fourfold NBS bromination of 3,3'-dimethylbiphenyl was refluxed in a mixture of water-ethanol (1:1) for $24 \mathrm{~h}$. The solution was then stirred overnight

Acta Chem. Scand. B 37 (1983) No. 4 
with sodium bisulfite and then extracted with chloroform several times. The aqueous layers were collected and acidified with sulfuric acid. After the gas evolution had ceased, the mixture was extracted with chloroform. The solvent was then distilled off giving 3,3'-biphenyldicarbaldehyde in $60 \%$ yield (m.p. $83-85^{\circ} \mathrm{C}$ ). NMR: $\delta$ $10.2(2 \mathrm{H}, \mathrm{s}), 8.3-7.5(8 \mathrm{H}, \mathrm{m})$. MS: $m / e 210\left(\mathrm{M}^{+}\right.$, $100 \%), 209$ (93), 182 (11), 181 (23).

The Wittig reactions were performed as previously described and the products were sepa- rated and isolated by the standard procedure. ${ }^{1}$

[2.0.2.0] Metacyclophanediene 1. 3,3'-Biphenyldicarbaldehyde $(3 \mathrm{mmol})$ and the bis(triphenylphosphonium) salt from 3,3'-bis(bromomethyl)biphenyl $(3 \mathrm{mmol})$ were reacted under the standard conditions to give cyclophane 1 , in $4 \%$ yield, (m.p. $114-115^{\circ} \mathrm{C}$ ). NMR: $\delta 7.61$ $\left(\mathrm{H}_{\mathrm{A}}, \mathrm{t}, J_{A B}=J_{A D}=1.5\right), 7.31\left(\mathrm{H}_{\mathrm{C}}, \mathrm{t}, J_{B C}=\right.$ $\left.J_{C D}=7.5\right), 7.18\left(\mathrm{H}_{\mathrm{B}}\right.$ or $\mathrm{H}_{\mathrm{C}}, \mathrm{d}$ of $\left.\mathrm{t}\right), 7.11\left(\mathrm{H}_{\mathrm{B}}\right.$ or $\mathrm{H}_{\mathrm{D}}, \mathrm{d}$ of $\left.\mathrm{t}\right)$ and $6.60\left(\mathrm{H}_{\mathrm{E}}, \mathrm{s}\right)$. MS: $\mathrm{m} / \mathrm{e} 356\left(\mathrm{M}^{+}\right.$, $100 \%), 355(6), 354(5), 353(6), 352(6), 351(6)$, 350 (6), $340(8), 339$ (9), 182 (11), $178(9), 176$ (10), 175 (9), 169.5 (12), 168.5 (13). Abs.mass; $356.156 \pm 0.003$; calc. for $\mathrm{C}_{28} \mathrm{H}_{20}$ 356.156. UV: $\lambda_{\max } 282 \mathrm{~nm}, \varepsilon=19500$.

[2.2.2.0]Metaparacyclophanediene 5. 4,4'-Bibenzyldicarbaldehyde $(3 \mathrm{mmol})$ and the bis(triphenylphosphonium) salt from 3,3'-bis(bromomethyl)biphenyl were reacted under the standard conditions to give cyclophane, 5 , in $4 \%$ yield (m.p. $\left.192{ }^{\circ} \mathrm{C}\right)$. NMR: $\delta 7.36\left(\mathrm{H}_{\mathrm{F}}, \mathrm{t}\right.$, $\left.J_{E F}=J_{F G}=7.5 \mathrm{~Hz}\right), 7.19\left(\mathrm{H}_{\mathrm{E}}, \mathrm{H}_{\mathrm{G}}, \mathrm{H}_{\mathrm{H}}, \mathrm{m}\right), 6.81$, $6.68\left(\mathrm{H}_{\mathrm{B}}\right.$ and $\left.\mathrm{H}_{\mathrm{C}}, \mathrm{d}, J_{B C}=8 \mathrm{~Hz}\right), 6.64,6.47\left(\mathrm{H}_{\mathrm{D}}\right.$ and $\left.\mathrm{H}_{\mathrm{D}^{\prime}}, \mathrm{d}, J_{D D^{\prime}}=12\right)$ and $2.87\left(\mathrm{H}_{\mathrm{A}}, \mathrm{s}\right)$. MS: $m / e$ $384\left(\mathrm{M}^{+}, 100 \%\right), 383$ (3), 192 (26), 91 (15). Abs.mass 384.187 \pm 0.003 ; calc. for $\mathrm{C}_{30} \mathrm{H}_{24}$ 384.187. UV: $262 \mathrm{~nm}, \varepsilon=24200$.

[2.2.2.2]Paracyclophanediene 6. Bibenzyl-4,4'dialdehyde $(5 \mathrm{mmol})$ and the bis(triphenylphosphonium) salt from 4,4'-bis(bromomethyl)biphenyl $(5 \mathrm{mmol})$ were reacted under the standard conditions to give cyclophane $6(156.5 \mathrm{mg}$, $15.2 \%$, m.p. $\left.137-139^{\circ} \mathrm{C}\right)$. NMR: $\delta 7.00$ and $6.73(16 \mathrm{H}, \mathrm{d}$, aromatic protons $), 6.53(4 \mathrm{H}, \mathrm{s}$, olefinic protons), and $2.84(8 \mathrm{H}$, s, methylene protons). MS (68 eV): m/e $412\left(\mathrm{M}^{+}, 100 \%\right), 207$ (20, 206 (80), 205 (18), and 191 (14). Abs.mass 412.222 \pm 0.005 ; calc. for $\mathrm{C}_{32} \mathrm{H}_{28}$ 412.219. UV (ethanol): $265 \mathrm{~nm}, \varepsilon=23600$.

Bi-4,5-phenanthrylene 2 . The cyclophanediene $l$ was dissolved together with iodine in cyclohexane and irradiated for $24 \mathrm{~h}$. The reaction products were separated by column chromatography on silica gel with tetrachloromethane as eluant, giving 2 in $65 \%$ yield (m.p. $262-263^{\circ} \mathrm{C}$ ). NMR: $\delta 7.80\left(\mathrm{H}_{\mathrm{B}}, \mathrm{d}\right.$, of $\left.\mathrm{d}, J_{B C}=J_{C D}=7.5\right), 7.66\left(\mathrm{H}_{\mathrm{A}}, \mathrm{s}\right)$,
$7.40\left(\mathrm{H}_{\mathrm{C}}, \mathrm{t}\right), 6.63\left(\mathrm{H}_{\mathrm{D}}, \mathrm{d}\right.$ of d, $\left.J_{B D}=1.4\right)$. MS: $m / e$ $352\left(\mathbf{M}^{+}, 67 \%\right), 351(80), 350(100), 349(13)$, 348 (27), 176 (7), 175.5 (13), 175 (47), 174.5 (7), 174 (27). Abs.mass 352.126 \pm 0.003 ; calc. for $\mathrm{C}_{28} \mathrm{H}_{16} 352.125$. UV: $253 \mathrm{~nm}, \varepsilon=100000$.

Dibenzo[def,pqr]cyclobutano[jkl]tetraphenylene 4. To a mixture of $2(8 \mathrm{mg})$ and sodium chloride $(30 \mathrm{mg})$ was added powdered aluminium chloride $(60 \mathrm{mg})$ and the compounds were mixed quickly. ${ }^{5}$ The reaction vessel was fitted with a drying tube and placed in a preheated oil bath at $140^{\circ} \mathrm{C}$. As soon as the melt was completed $(10$ $\mathrm{min})$ it was hydrolyzed with water $(20 \mathrm{ml})$. The water phase was extracted with chloroform several times and the combined organic phases evaporated to dryness. The residue was chromatographed on silica gel with chloroform as eluant giving 4 in $40 \%$ yield (m.p. $330{ }^{\circ} \mathrm{C}$ decomp.). NMR: $\delta 9.34\left(\mathrm{H}_{\mathrm{G}}\right.$ or $\left.\mathrm{H}_{\mathrm{F}}, \mathrm{d}, J_{F G}=8.5\right), 9.15\left(\mathrm{H}_{\mathrm{A}}\right.$ or $\mathrm{H}_{\mathrm{C}}, \mathrm{d}$ of $\mathrm{t}, J_{B C}$ or $\left.J_{A B}=7.5\right), 8.52\left(\mathrm{H}_{\mathrm{G}}\right.$ or $\mathrm{H}_{\mathrm{F}}$, d), $8.27\left(\mathrm{H}_{\mathrm{A}}\right.$ or $\mathrm{H}_{\mathrm{C}}$, d of $\left.\mathrm{t}\right), 8.23\left(\mathrm{H}_{\mathrm{D}}\right.$ and $\mathrm{H}_{\mathrm{E}}$, $\mathrm{AB}$-quartet, $\left.J_{D E}=8\right)$ and $8.13\left(\mathrm{H}_{\mathrm{B}}, \mathrm{t}\right)$. MS: $m / e$ $350\left(\mathrm{M}^{+}, 37 \%\right), 348(7), 175(16), 123(15), 109$ (24). Abs.mass $350.109 \pm 0.003$; calc. for $\mathrm{C}_{28} \mathrm{H}_{14}$ 350.109 .

Acknowledgements. We thank Mrs. I. Raston for skilful technical assistance and the Swedish Natural Science Research Council for financial support.

\section{REFERENCES}

1. Thulin, B., Wennerström, O., Somfai, I. and Chmielarz, B. Acta Chem. Scand. B 31 (1977) 135; Thulin, B., Wennerström, O. and Somfai, I. Acta Chem. Scand. B 32 (1978) 109.

2. Thulin, B. and Wennerström, O. Tetrahedron Lett. (1977) 929.

3. Leach, D. N. and Reiss, J. A. J. Org. Chem. 43 (1978) 2484.

4. Irngartinger, H., Reibel, W. R. K. and Sheldrick, G. M. Acta Crystallogr. B 37 (1981) 1768.

5. Dopper, J. H. and Wynberg, H. Tetrahedron Lett. (1972) 763.

6. Dopper, J. H. and Wynberg, H. J. Org. Chem. 40 (1975) 1957.

7. For a discussion of some related examples, see Thulin, B. and Wennerström, O. Acta Chem. Scand. B 37 (1983). In press.

8. Ankner, K., Lamm, B., Thulin, B. and Wennerström, O. Acta Chem. Scand. B 33 (1979) 391. 
9. Tanner, D. and Wennerström, O. Tetrahedron Lett. (1981) 2313.

10. Olsson, T., Tanner, D., Thulin, B., Wennerström, O. and Liljefors, T. Tetrahedron 37 (1981) 3473.

11. Thulin, B. and Wennerström, O. Acta Chem. Scand. B 30 (1976) 369 and unpublished results.

Received August 2, 1982. 